\title{
Fixed Base Modal Testing Using the NASA GRC Mechanical Vibration Facility
}

\author{
Lucas D. Staab, James P. Winkel, Vicente J. Suárez, Trevor M. Jones \\ NASA Glenn Research Center \\ 21000 Brookpark Road \\ Cleveland, Ohio 44135
}

\author{
Kevin L. Napolitano \\ ATA Engineering, Inc. \\ 13290 Evening Creek Drive South, Suite 250 \\ San Diego, California 92128
}

\begin{abstract}
The Space Power Facility at NASA's Plum Brook Station houses the world's largest and most powerful space environment simulation facilities, including the Mechanical Vibration Facility (MVF), which offers the world's highest-capacity multi-axis spacecraft shaker system. The MVF was designed to perform sine vibration testing of a Crew Exploration Vehicle (CEV)-class spacecraft with a total mass of 75,000 lb, center of gravity (cg) height above the table of $284 \mathrm{in}$., diameter of $18 \mathrm{ft}$, and capability of $1.25 \mathrm{~g} \mathrm{pk}$ in the vertical and $1.0 \mathrm{~g}$ pk in the lateral directions. The MVF is a six-degree-of-freedom, servohydraulic, sinusoidal base-shake vibration system that has the advantage of being able to perform single-axis sine vibration testing of large structures in the vertical and two lateral axes without the need to reconfigure the test article for each axis. This paper discusses efforts to extend the MVF's capabilities so that it can also be used to determine fixed base modes of its test article without the need for an expensive test-correlated facility simulation.
\end{abstract}

Keywords: modal testing, vibrations, base-shake, environmental testing, fixed base

\section{INTRODUCTION}

The Space Power Facility (SPF) is the home of the world's largest and most powerful space environment simulation facilities. The Space Simulation Vacuum Chamber is the world's largest, measuring 329 meters (100 ft) in diameter by $400 \mathrm{~meters}$ (122 ft) high. The Reverberant Acoustic Test Facility (RATF) is the world's most powerful spacecraft acoustic test chamber, and the Mechanical Vibration Facility (MVF) is the world's highest-capacity and most powerful spacecraft shaker system. The SPF

is located at the NASA Glenn Research Center, Plum Brook Station, in Sandusky, Ohio. An aerial photograph of the SPF is shown in Fig 1. 


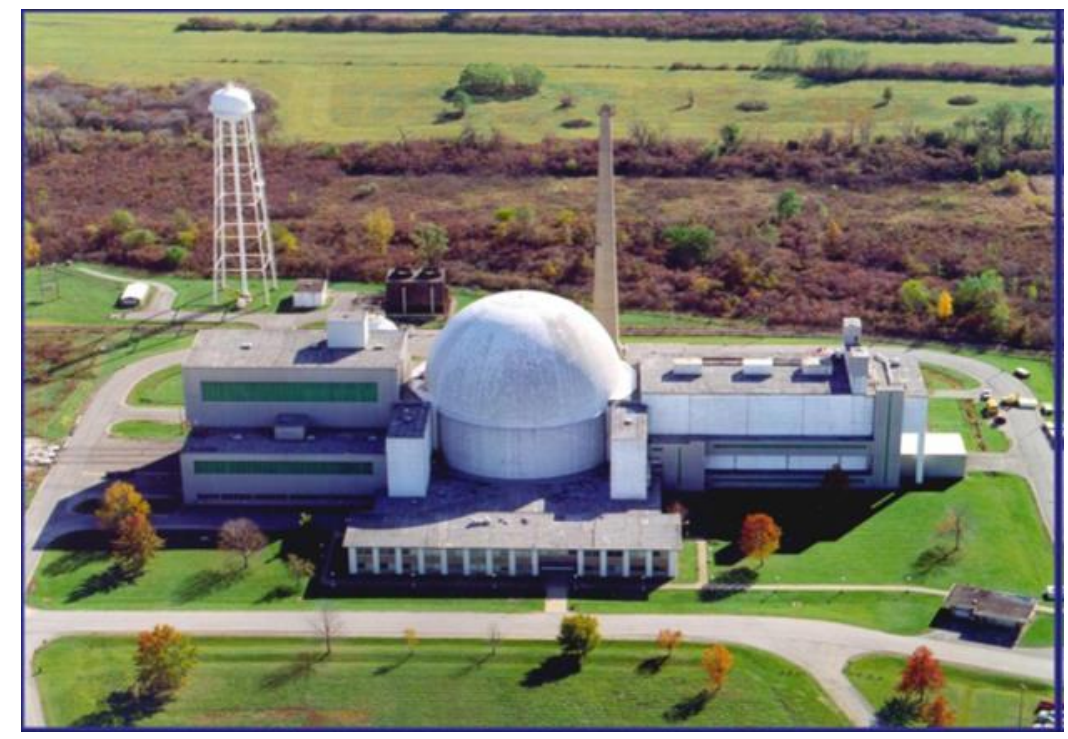

Fig 1 Aerial View of Space Power Facility

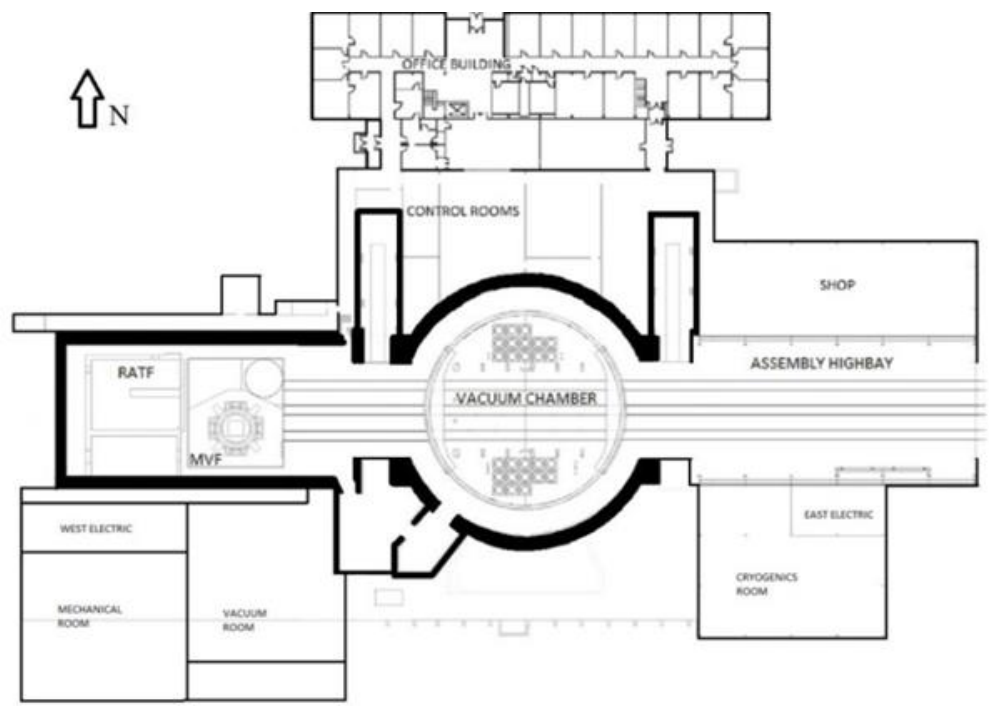

Fig 2 Plan View of Plum Brook Station

A plan view of the SPF is shown in Fig 2. The highbay on the east side of the SPF, the Assembly Highbay, is primarily used for receiving, assembling, and preparing test hardware. The Vibroacoustic Highbay on the west side of the facility (formerly the Disassembly Highbay) houses the Mechanical Vibration Facility (MVF) and the Reverberant Acoustic Test Facility (RATF). North and south of the vacuum chamber and highbays are various supporting areas. North of the vacuum chamber are the facility control rooms, signal conditioning and instrumentation areas, machine shop, and a two-story office building. South of the vacuum chamber are the electric substations, cryogenics room, vacuum room, and mechanical rooms. The south outdoor courtyard areas behind the SPF support the liquid and gaseous nitrogen storage bottles, vaporizers, and cooling tower.

The test hardware was received and primarily assembled in the SPF assembly area. The room is temperature and humidity controlled. The SPF assembly area has a data acquisition area, a loading/handling area of about $46 \mathrm{~m}$ (150 ft) x $23 \mathrm{~m}$ (75 ft),

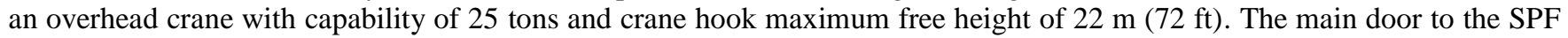
is located on the east side of the lab and has dimensions of $15.2 \mathrm{~m}(50 \mathrm{ft})$ tall x $15.2 \mathrm{~m}(50 \mathrm{ft})$ wide. 


\section{Mechanical Vibration Facility (MVF)}

The MVF is a three-axis vibration system that consists of reaction mass, four airbags, four horizontal servohydraulic actuators, sixteen vertical servohydraulic actuators mounted on double spherical couplings, aluminum table, hydraulic supply system, Table Control System (TCON), Vibration Control System (VCON), and the same Facility Control System (FCS) used by the RATF. The MVF was designed to perform sine vibration testing of a CEV-class spacecraft with a total mass of 75,000 $\mathrm{lb}$, center of gravity (cg) height above the table of 284 in., diameter of $18 \mathrm{ft}$, and capability of $1.25 \mathrm{~g}$ pk in the vertical and $1.0 \mathrm{~g}$ pk in the lateral directions.

The MVF will apply vibration in each of the three orthogonal axes (not simultaneously) with one direction in parallel to the Earth-launch thrust axis at 5-150 Hz, 0-1.25 g-pk vertical, and 5-150 Hz, 0-1.0 g-pk for the horizontal axes. Vertical, or the thrust axis, shaking is accomplished by using sixteen vertical actuators manufactured by TEAM Corporation, each capable of a dynamic force of $133 \mathrm{~K}$-Newton $(30,000 \mathrm{lbf})$. The sixteen vertical actuators allow for testing of up to a 34,019 $\mathrm{kg}(75,000 \mathrm{lb})$ article at the previously stated frequency and amplitude limits. The sixteen vertical actuators are locked out during horizontal shaking. Horizontal shaking is accomplished through use of four TEAM Corporation horizontal actuators; two in each direction, each capable of a dynamic force of $380 \mathrm{~K}-\mathrm{Newton}(85,400 \mathrm{lbf})$. The horizontal actuators are used during vertical testing to counteract cross-axis forces and overturning moments. Additionally, the MVF provides excitation, control, and data acquisition and processing capabilities. Fig 3 shows the MVF plan view. This vibration system is anchored to a reaction mass of 2,041 tons (4.5 million pounds), which itself is secured to the underlying ground via rock bolts. MVF can support up to eight drive signals (i.e., independent references), up to twelve control accelerometers (i.e., control inputs), up to a total of 32 response limiting channels, and another 32 monitoring channels.

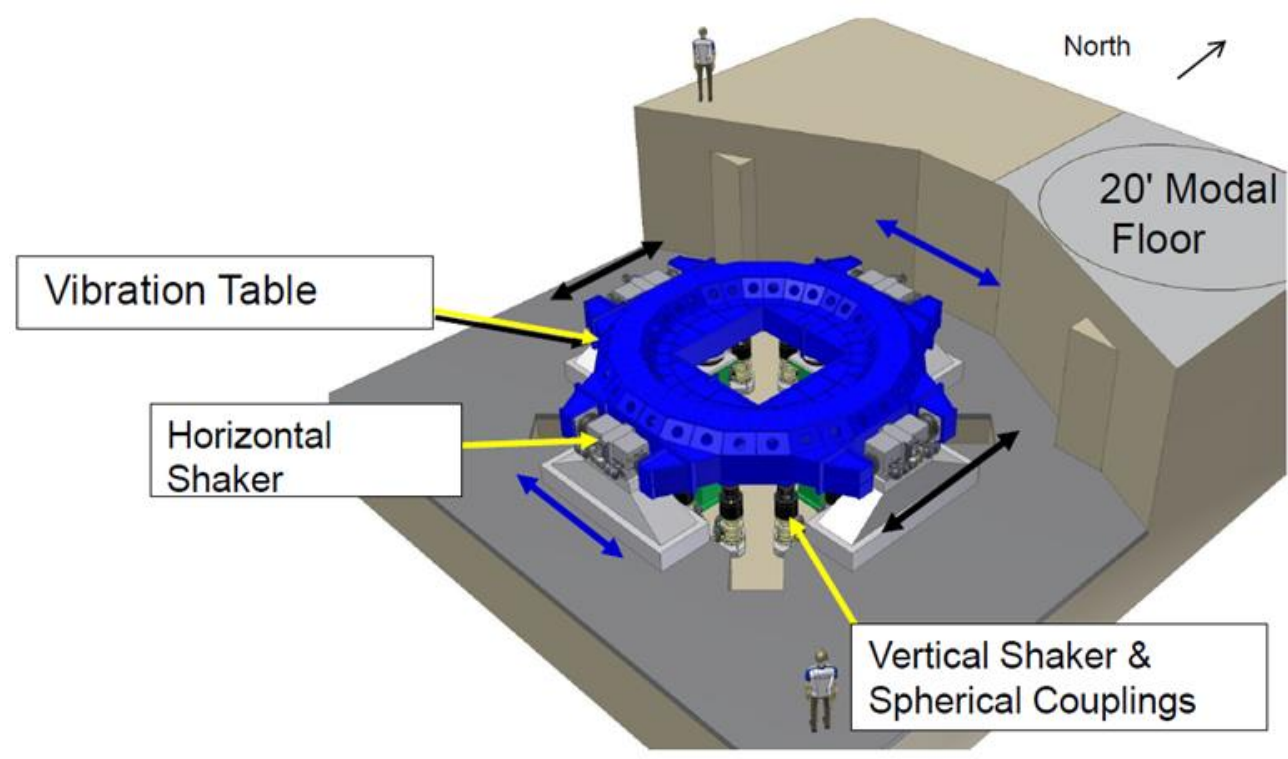

Fig 3 Plan View of MVF Three-Axis Base Shake Table

This paper discusses efforts to use the MVF to conduct modal tests which yield fixed base results, including characterization of the MVF table dynamics, and methods to extend the usable frequency range of the table for modal tests.

\section{REVIEW OF FIXED BASE CORRECTION TECHNIQUES}

The desire to extract fixed base modes from structures mounted on shake tables has received a great deal of attention in recent years [1]-[7]. Difficulties arise when the shake table moves in more than one direction, such as when the inertia forces imparted by the test article cause the table to rock at the combined system natural frequency rather than the test article fixed base natural frequency.

Currently, there are two promising methods that account for shake table motion. The first, developed by Sandia National Laboratories [8], is a transformation of measured modes to fixed base modes, and the second, developed by ATA Engineering [9], uses shake table accelerations as references when calculating FRFs. The key element in both methods is using a small number of shapes that adequately describe shaker table motion. 


\section{Mode Shape Correction Method}

The first method, hereafter called the mode shape correction method, assumes that fixed base modes are a linear combination of the test-measured mode shapes. Conceptually, a coordinate transformation matrix between the measured modes and the resultant fixed base modes is calculated by enforcing a constraint that the base does not move. In practice, the constraint is relaxed to a small number of shapes associated with the largest motion of the shake table.

Once the shapes are defined, the coordinate transformation matrix is calculated and used to turn the equation of motion in modal coordinates to the fixed base equation of motion. Natural frequency, damping, and fixed base shapes in modal coordinates are then solved for from the fixed base equation of motion.

\section{FRF Correction Method}

The second method, hereafter called the FRF correction method, uses a small number of shapes associated with the largest motion of the shake table as virtual degrees of freedom. A coordinate transformation matrix defining the linear relationship between the physical degrees of freedom on the shaker table and the virtual degrees of freedom associated with the shape is created by taking the pseudo-inverse of these shapes. Virtual channels are created by applying the coordinate transformation to the measured time-history functions, and then these channels, along with load cells associated with shakers mounted on the test article, are used as references when calculating frequency response functions. Fixed base modes are then estimated using modal analysis techniques. In practice, there must be at least as many linearly independent excitations applied to the table as there are deformed shapes used as references.

Some advantages and disadvantages to using both methods are presented in Table 1. The mode shape correction method requires that the modal mass must be calculated as one of the modal parameters, which means the peaks in the FRF must be clearly defined in the drive point FRF. It also requires that the fixed base modes must be a linear combination of the measured mode shapes; the accuracy of the method degrades as this requirement is violated. The clear advantage of using this method, however, is that the number of shapes used to define the table deformations is not limited to the number of excitations applied to the table. On the other hand, the major drawback of the FRF correction method is that the number of table shapes is limited by the number of linearly independent excitations applied to the table. The advantage is that fixed base modes are calculated directly from the calculated fixed base FRF.

Table 1 Comparison of Mode Shape Correction and FRF Correction Methods

\begin{tabular}{|l|c|l|}
\hline METHOD & Mode Shape Correction & FRF Correction \\
\hline Advantages & $\begin{array}{l}\text { Number of constraint shapes not } \\
\text { limited to number of shakers. }\end{array}$ & $\begin{array}{l}\text { Direct measurement of fixed } \\
\text { base modes. }\end{array}$ \\
\hline Disadvantages & $\begin{array}{l}\text { Modal mass must be calculated. } \\
\text { Fixed base modes must be } \\
\text { linear combination of measured } \\
\text { modes. }\end{array}$ & $\begin{array}{l}\text { Number of constraint shapes } \\
\text { must be less than or equal to the } \\
\text { number of exciters mounted to } \\
\text { the shaker table. }\end{array}$ \\
\hline
\end{tabular}

\section{Determination of Table Shapes}

The key to both methods is using a reduced set of shapes to describe table motion. A single optimal method for determining these shapes has not yet been defined, and there are several ways to calculate the shapes. All methods involve parsing test or analysis data down to the degrees of freedom that measure table motion. A list of shape estimation options is as follows:

1. Singular value decomposition (SVD) of time-history functions

2. SVD of FRFs

3. SVD of analysis mode shapes

4. A set of analysis mode shapes

5. SVD of test measured mode shapes

6. A set of test measured mode shapes

7. Calculation of rigid body shapes based on geometry

8. Measured rigid body shapes from test 
One can use any combination of these methods to define the table shapes. The accuracy of the final results is commensurate with how well these estimates reflect the actual table motion.

\section{MODAL TEST OF FREE-FREE BARE MVF TABLE}

Fig 4 shows the MVF and actuators. In the back of the photograph is the MVF table, which is currently installed on the actuators.

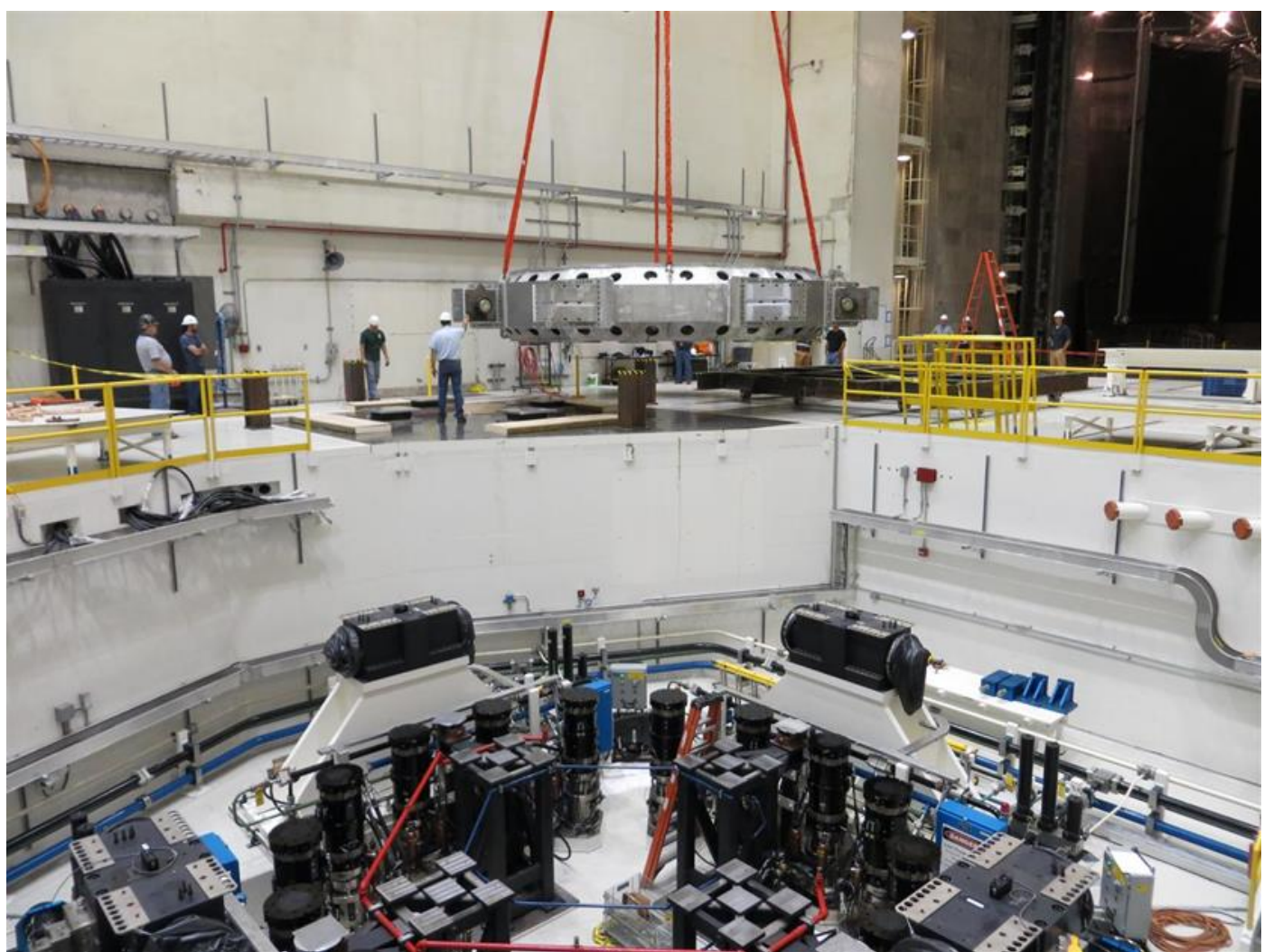

Fig 4 MVF Table (Above) Separated from MVF Pit (Below) Containing Actuators and Support Structure

Fig 5 is the assembled MVF table. This is the test article for this modal survey. The torus-shaped center of the table is a onepiece 5083 aluminum weldment. Eight "ears" (also 5083 aluminum) are fastened to the center weldment. Additionally, there are a total of eight ballast plates that can be added to the table. The assembled table with no ballast plates weighs 23.51 metric tons $(51,826 \mathrm{lbs})$. The assembled table is approximately 1.2 meter x 7.9 meter x 7.9 meter (4' x 26' x 26'). 


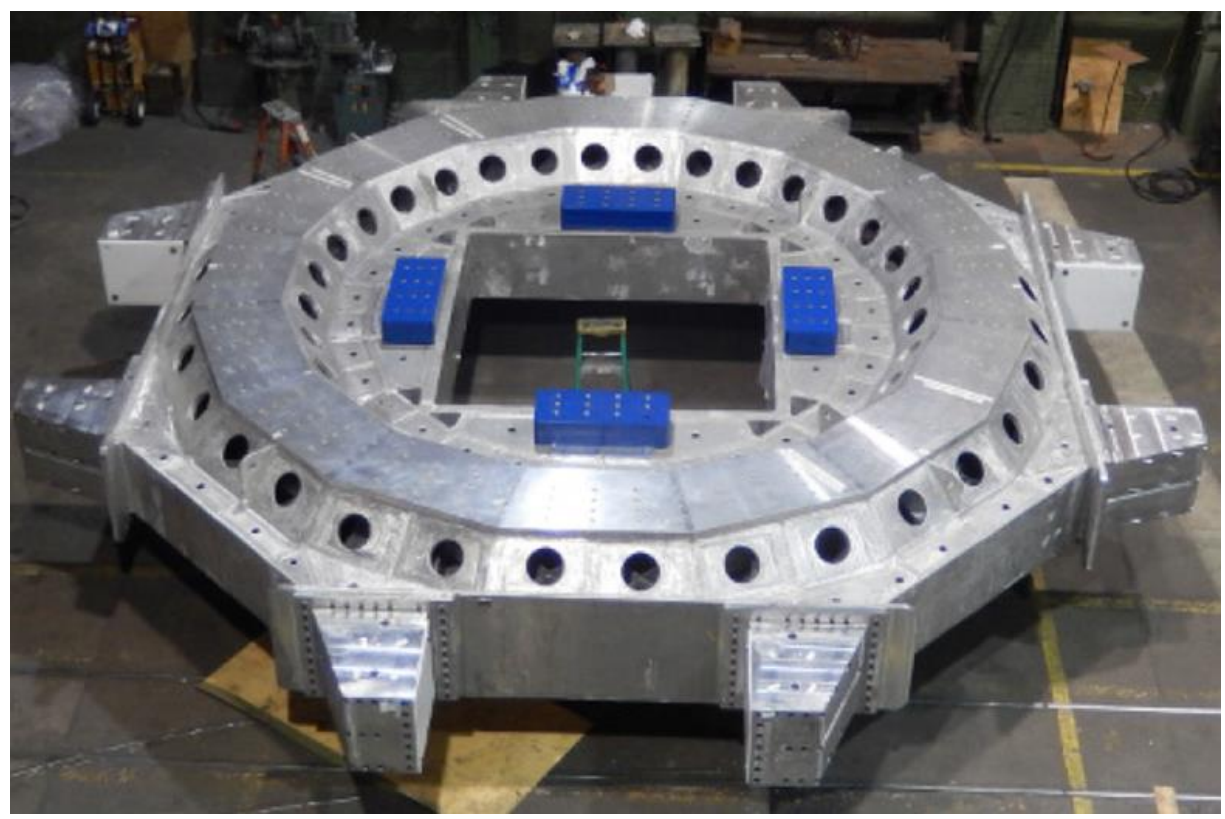

Fig 5 MVF Table Resting on Airbags

\section{Test Setup}

The test setup is intended to simulate close to a free-free boundary condition. The table is mounted on airbags. There are four large airbags under the table supporting it in the vertical direction (Fig 6), and there are four additional airbags providing lateral support (Fig 7). The lateral airbags are mounted to every other table ear. A stability analysis was completed to ensure that the table would remain suspended and not tip over.

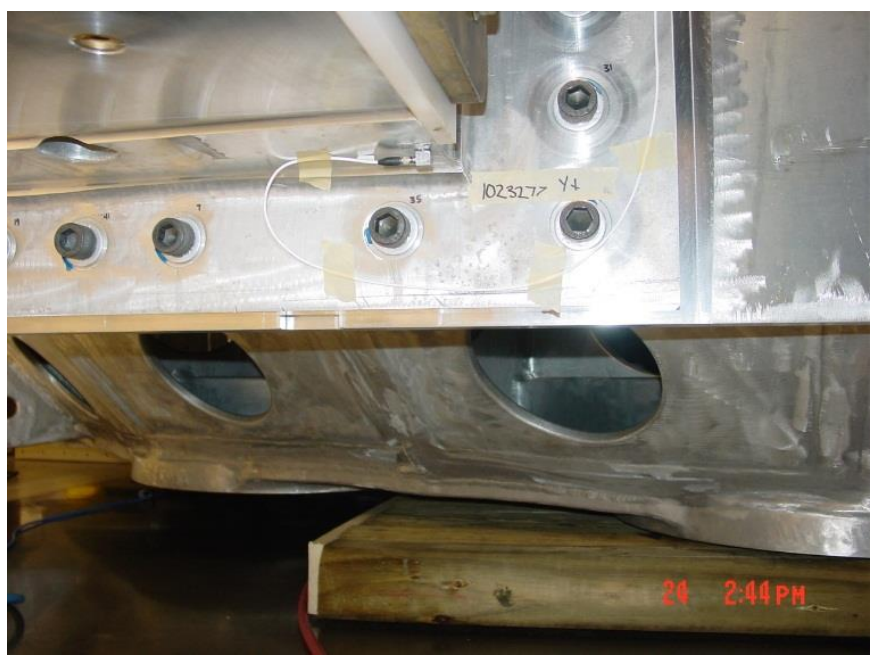

Fig 6 Vertical Airbags 


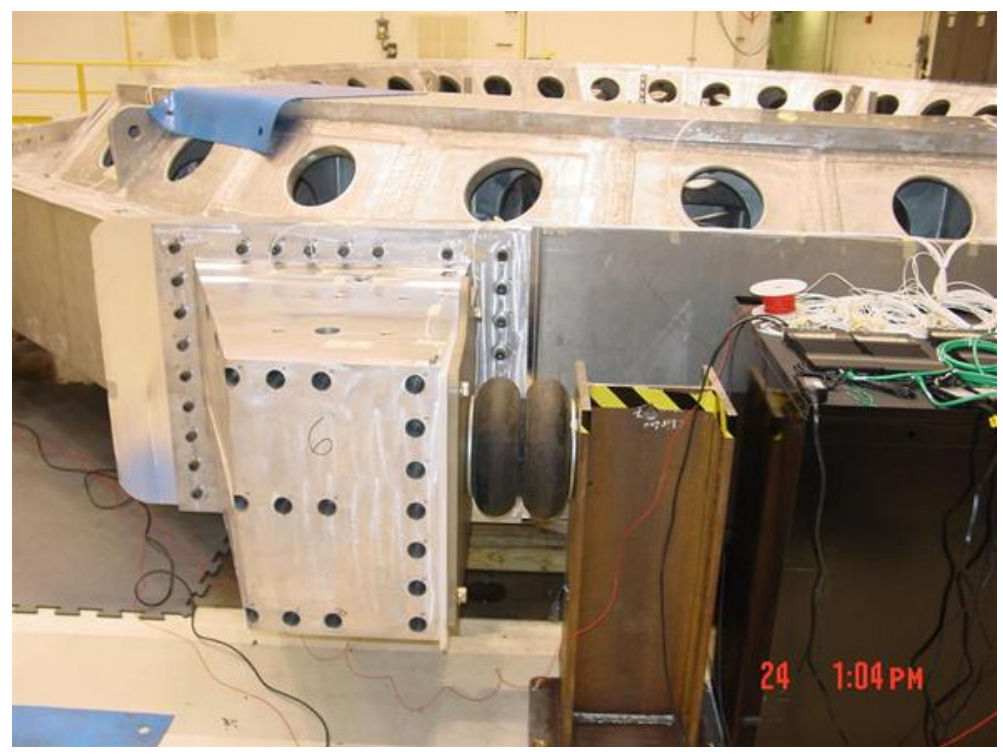

Fig 7 Horizontal Airbags

\section{Instrumentation}

Modal hammer: A large-sized modal hammer (PCB 086C50) with a brown rubber medium-soft tip was used to tap on the MVF table.

Response accelerometers: Up to 66 response accelerometers were mounted to the MVF table to capture the dynamic responses. A drive point response accelerometer located close to the tapping point of the modal hammer was also used. If the drive point did not correspond to an existing response accelerometer location, an additional accelerometer was mounted at the drive location of impact for each point of impact, or an existing nearby response accelerometer was used. All instrumentation was in calibration.

\section{Test Results}

A modal pretest analysis was performed on the MVF table using the test configuration finite element model (FEM), and a test analysis model (TAM) for test configuration 1 was produced. The TAM consists of the selection and location of test degrees of freedom, the associated test display model (TDM) that is used to visually display mode shapes, the reduced FEM produced by reducing the full FEM to the test DOF using a Guyan reduction, the mass and stiffness matrices of the reduced FEM used to compute the cross-orthogonalities (x-orthos) between the full FEM and reduced FEM mode shapes, and the $\mathrm{x}$-orthos themselves. The TDM for all test configurations is shown in Fig 8.

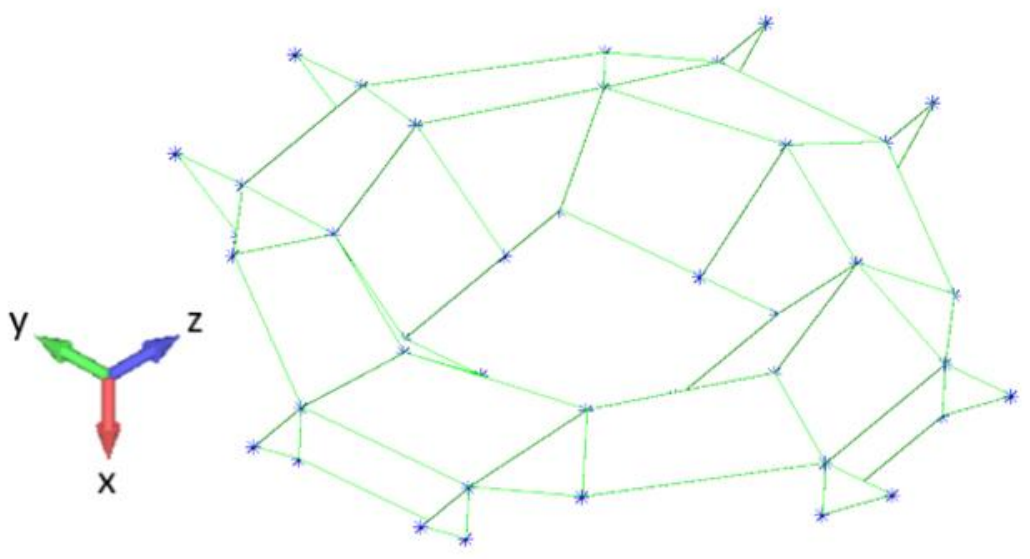

Fig 8 MVF Table Test Display Model 
Fig 9 shows the full FEM from which the TDM was derived.

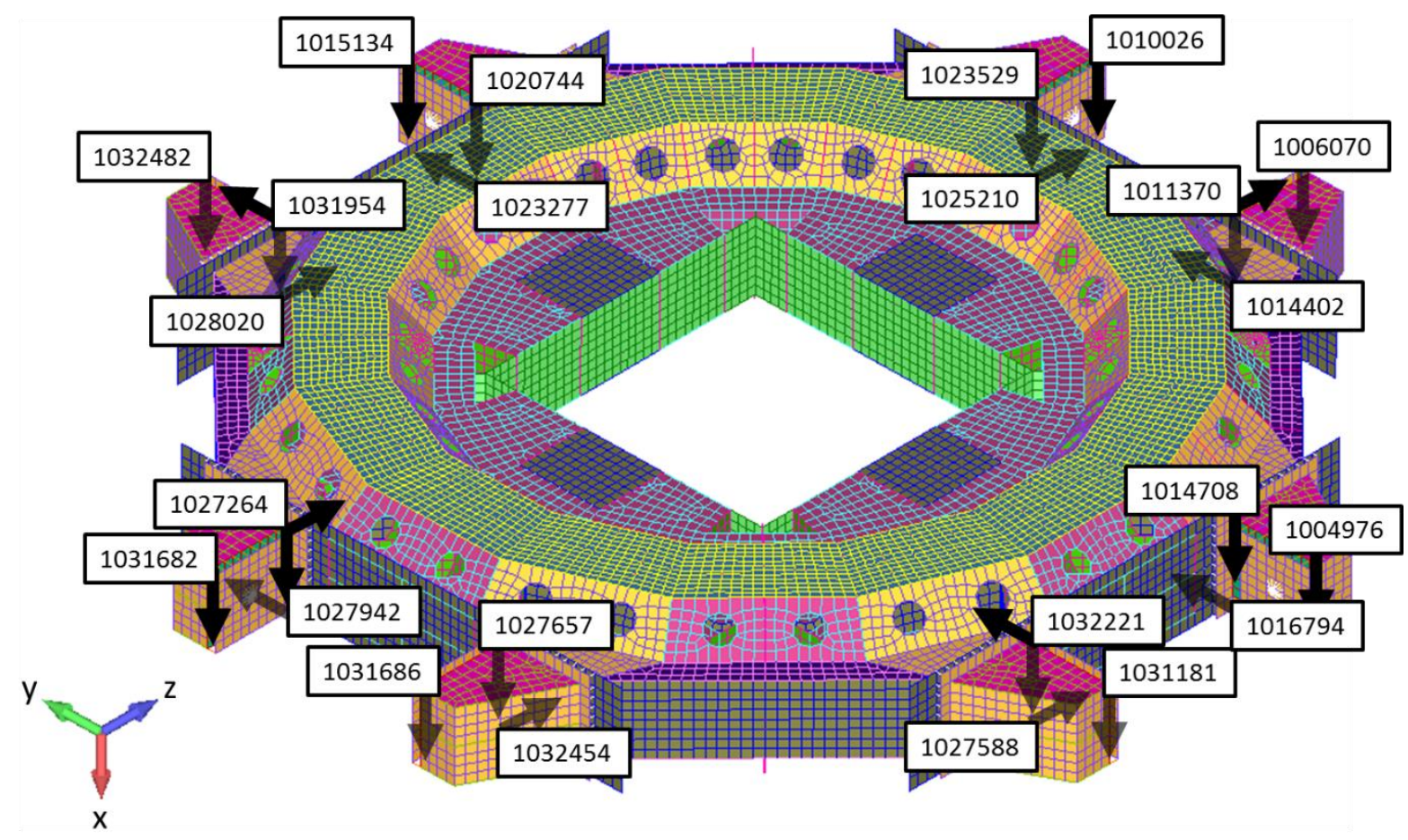

Fig 9 MVF Table Full Finite Element Model

The pretest cross-orthogonality table is shown in Table 2. This x-ortho table shows that the test DOF are sufficient to capture the desired FEM mode shapes and support a model correlation effort.

Table 2 Pretest Analysis X-Ortho Table

\begin{tabular}{|c|c|c|c|c|c|}
\hline Mode & $\mathrm{Hz}$ & $\mathrm{Hz} \%$ diff & PORTHO & XORTHO & Mode Shape Description \\
\hline 7 & 50.24 & 1.3 & 95.25 & 99.90 & Potato Chip $+/$ - $Z$ ears in-phase oposite of $+/$ - $Y$ ears \\
\hline 8 & 53.12 & 1.8 & 92.74 & 99.83 & Potato Chip $+Y Z /-Y Z$ corners in-phase oposite of $+Y-Z /-Y+Z$ \\
\hline 9 & 90.60 & 5.2 & 70.11 & 99.98 & Squeeze Mode (motion in $Y Z$ plane only) $+Y Z /-Y Z$ corners in-phase oposite of $+Y-Z /-Y+Z$ \\
\hline 10 & 97.69 & 4.0 & 85.86 & 99.91 & Oil can mode \\
\hline 11 & 107.92 & 4.8 & 82.30 & 99.82 & $"+Y-Z /-Y+Z$ ear torsion about $+Y-Z$ axis \\
\hline 12 & 107.92 & 4.7 & 82.60 & 99.83 & $"+Y Z /-Y Z$ ear torsion about $+Y Z$ axis \\
\hline 13 & 116.52 & 5.4 & 69.66 & 99.90 & Squeeze Mode (motion in $Y Z$ plane only) $+1-Z$ ears in-phase oposite of $+1-Y$ ears \\
\hline 14 & 133.58 & 5.9 & 79.45 & 99.66 & Every Ear out bending out-of-phase with adjacent ear \\
\hline 15 & 138.34 & 5.8 & 68.29 & 73.95 & Second oil can mode (two lobes in Y-Direction) \\
\hline 16 & 138.34 & 5.4 & 68.39 & 73.80 & Second oil can mode (two lobes in Z-Direction) \\
\hline
\end{tabular}

\begin{tabular}{|c|}
\hline Key: \\
\hline Mode Pair \\
\hline
\end{tabular}

Modal survey testing was conducted using several different impact points in order to excite the modes of interest. The impact locations were selected using engineering judgment based on the FEM mode shapes seen. The tapping locations are shown in Fig 10. Impact location 1 was at the top face of the southeast ear in the $+\mathrm{X}$ axis. Impact location 11 was at the north outward face between the ears in the $-\mathrm{Z}$ axis. Upon postprocessing the data, it was shown that impact location 1 captured all the modes of interest. 


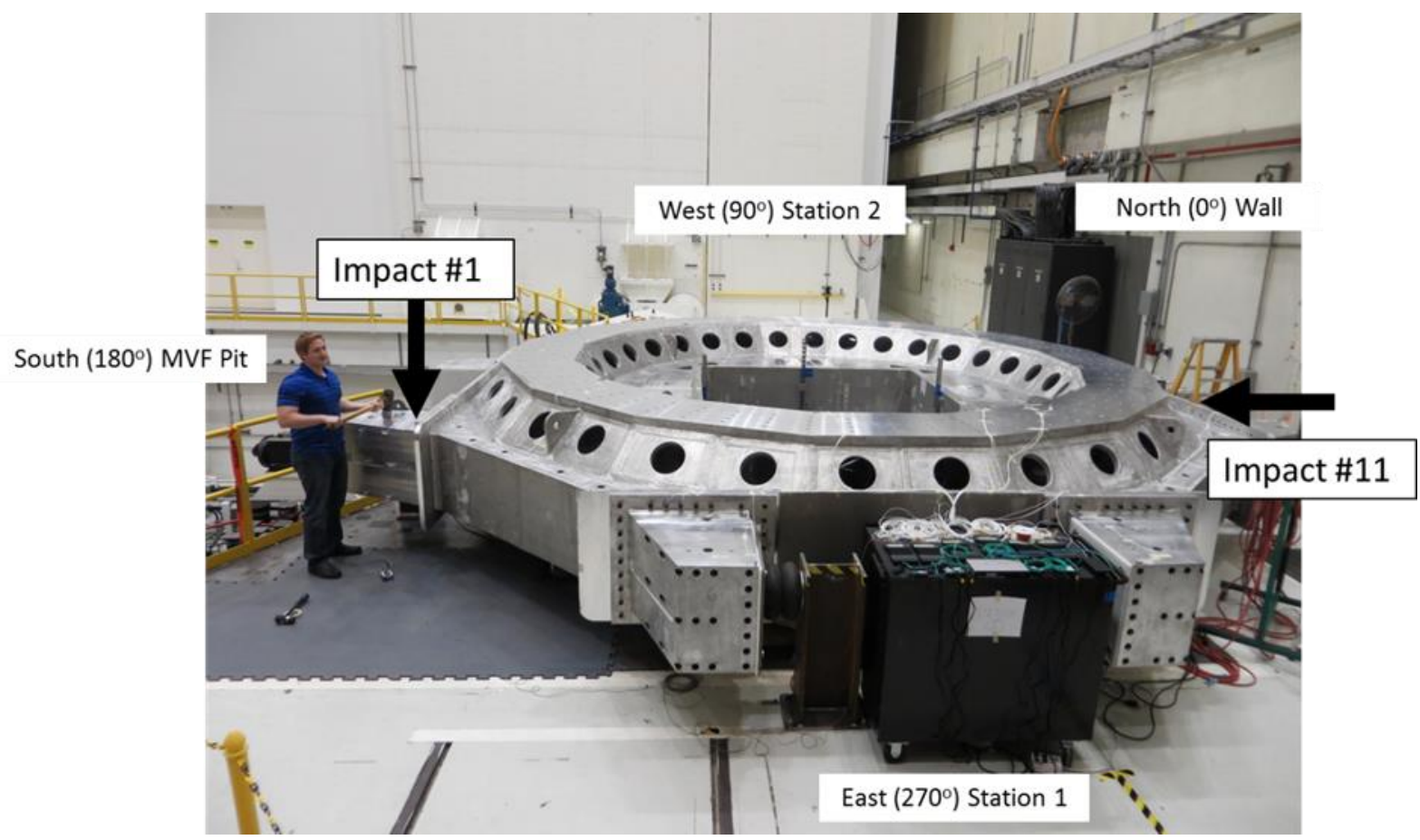

Fig 10 Impact Locations

Modal extraction was relatively straightforward for this test and did not require any manual "tweaking" of the extracted modal parameters. Table 3 lists all of the extracted modes, and parameters used for all of the modes extracted.

Table 3 Bare Table Test Modal Parameters

\begin{tabular}{|l|l|l|l|}
\hline MODAL & PARAMETERS & & \\
\hline ID1: & Polyreference, & REF: & $1 \mathrm{X}+$, \\
\hline PARM & SHAPE & FREQUENCY & DAMPING \\
\hline LABEL & REC & \multicolumn{1}{l|}{ (HERTZ) } & $(\%)$ \\
\hline 1 & 1 & 52.727 & 0.048 \\
\hline 2 & 2 & 54.978 & 0.112 \\
\hline 1 & 11 & 96.187 & 0.034 \\
\hline 4 & 4 & 102.851 & 0.065 \\
\hline 5 & 5 & 111.015 & 0.314 \\
\hline 6 & 6 & 114.839 & 0.057 \\
\hline 1 & 1 & 123.766 & 0.31 \\
\hline 1 & 8 & 140.753 & 0.047 \\
\hline 2 & 9 & 142.018 & 0.054 \\
\hline 3 & 10 & 144.334 & 0.042 \\
\hline
\end{tabular}

\section{FINITE ELEMENT MODEL UPDATING}

An initial cross-orthogonality ( $\mathrm{x}$-ortho) between experimental and analytical modal vectors was calculated to check the adequacy of the FEM. Table 4 shows a small frequency error on mode 5 and small cross-talk in a few modes. Ideally, the goals for acceptable correlation are absolute values of diagonal terms greater than 0.9 with absolute values for all off-diagonal terms being less than 0.1 for significant modes. For the fundamental frequency, the goal in each axis is \pm 5 percent, while the correlation goal for higher-order frequencies is agreement within \pm 10 percent. 
Table 4 Initial X-Ortho Matrix

\begin{tabular}{|c|c|c|c|c|c|c|c|c|c|c|c|c|c|}
\hline & & & \multicolumn{11}{|c|}{ Analysis Modes } \\
\hline & Mode \# & & 7 & 8 & 9 & 10 & 12 & 11 & 13 & 14 & 16 & 15 & Frequency \\
\hline & & Freq $(\mathrm{Hz})$ & 50.29 & 53.25 & 91.05 & 97.91 & 108.00 & 108.00 & 116.93 & 133.70 & 139.02 & 139.02 & $\%$ Error \\
\hline \multirow{10}{*}{ 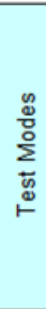 } & 1 & 52.73 & 1.00 & 0.007 & 0.091 & actan & action & 0.000 & 0.001 & 0.0007 & 0.079 & (0.097) & $-4.62 \%$ \\
\hline & 2 & 54.98 & 0.06 & 1.00 & 0.001 & 0,000 & 0.011 & (1).010 & 0.011 & 0.011 & 003 & 0,001 & $-3.15 \%$ \\
\hline & 3 & 96.19 & 000 & 0,02 & 1.00 & 00 & 00 & 00 & 00 & 000 & 0,04 & 001 & $-5.34 \%$ \\
\hline & 4 & 102.85 & 0,00 & 00 & 0.04 & 0.99 & 06 & 00 & 0,000 & 0.00 & 0.02 & 00 & $-4.81 \%$ \\
\hline & 5 & 111.01 & 0,01 & 0,00 & 0,01 & 0.091 & 0.99 & 0.14 & 0,00 & 0.01 & 0,02 & 0,07 & $-2.72 \%$ \\
\hline & 6 & 114.84 & 00.006 & $0,0,000$ & (60.061 & 0.011 & 0.17 & 0.97 & 00.001 & 0.000 & 0.13 & (1010) & $-5.96 \%$ \\
\hline & 7 & 123.77 & 0,012 & 0.001 & 0.03 & 0,000 & 0,010 & 0.010 & 1.00 & 0.011 & 0.02 & $0,0,2$ & $-5.52 \%$ \\
\hline & 8 & 140.75 & 0.112 & 0,00 & 0.07 & 0.00 & 0.00 & 0.08 & 0.015 & 0.99 & 0.11 & 0.06 & $-5.01 \%$ \\
\hline & 9 & 142.02 & 0.000 & 0.011 & 0.001 & 0.000 & (1) 600 & $0,0.05$ & 0.015 & 0.15 & 0.97 & 0.011 & $-2.11 \%$ \\
\hline & 10 & 144.33 & 0,00 & 0.00 & 0.00 & 0.04 & 0.04 & 0,012 & 0.012 & 0.05 & 0.07 & 0.98 & $-3.68 \%$ \\
\hline
\end{tabular}

Part of the correlation effort was to update the FEM and rerun the x-ortho until the correlation goals were achieved. The lateral stiffness of the airbags was changed to match the actual test configuration, the density of the table was changed to represent the actual mass of the hardware, the horizontal actuator attachment plates were removed in the FEM, and four horizontal airbag ear plate attachments were added in the FEM to represent test configuration 1. After making those changes x-ortho was again calculated, and it is shown in Table 5. This table shows that the goals were achieved.

Table 5 Final X-Ortho Matrix for MVF Table

\begin{tabular}{|c|c|c|c|c|c|c|c|c|c|c|c|c|c|}
\hline & & & \multicolumn{10}{|c|}{ Analysis Modes } & \\
\hline & Mode \# & & 7 & 8 & 9 & 10 & 11 & 12 & 13 & 14 & 15 & 16 & Frequency \\
\hline & & Freg $(\mathrm{Hz})$ & 52.78 & 55.60 & 94.77 & 102.39 & 111.84 & 114.98 & 122.11 & 140.80 & 144.22 & 146.27 & Error \% \\
\hline \multirow{10}{*}{ 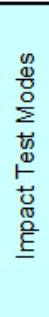 } & 1 & 52.73 & 1.00 & 0.04 & 0.09 & 0.00 & 0.00 & 0.00 & 0.01 & 0.00 & 0.03 & 0.04 & $0.10 \%$ \\
\hline & 2 & 54.98 & 0.05 & 1.00 & 0.04 & 0.00 & 0.09 & 0.00 & 0.01 & 0.02 & 0.03 & 0.04 & $1.13 \%$ \\
\hline & 3 & 96.19 & 0.00 & 0.02 & 1.00 & 0.05 & 0.09 & 0.02 & 0.03 & 0.04 & 0.01 & 0.01 & $-1.47 \%$ \\
\hline & 4 & 102.85 & 0.00 & 0.01 & 0.01 & 0.99 & 0.03 & 0.01 & 0.00 & 0.00 & 0.02 & 0.02 & $-0.45 \%$ \\
\hline & 5 & 111.01 & 0.00 & 0.00 & 0.01 & 0.04 & 1.00 & 0.03 & 0.01 & 0.04 & 0.02 & 0.00 & $0.74 \%$ \\
\hline & 6 & 114.84 & 0.00 & 0.00 & 0.01 & 0.01 & 0.04 & 0.99 & 0.01 & 0.08 & 0.14 & 0.03 & $0.12 \%$ \\
\hline & 7 & 123.77 & 0.02 & 0.00 & 0.03 & 0.00 & 0.000 & 0.01 & 1.00 & 0.04 & 0.02 & 0.02 & $-1.33 \%$ \\
\hline & 8 & 140.75 & 0.02 & 0.00 & 0.01 & 0.04 & 0.02 & 0.02 & 0.03 & 0.99 & 0.11 & 0.04 & $0.03 \%$ \\
\hline & 9 & 142.02 & 0.00 & 0.04 & 0.01 & 0.00 & 0.04 & 0.04 & 0.03 & 0.15 & 0.97 & 0.07 & $1.55 \%$ \\
\hline & 10 & 144.33 & 0.00 & 0.00 & 0.02 & 0.01 & 0.03 & 0.02 & 0.02 & 0.05 & 0.05 & 0.98 & $1.34 \%$ \\
\hline
\end{tabular}

Fig 11 shows the mode shapes of the correlated FEM without the ballast plates. 


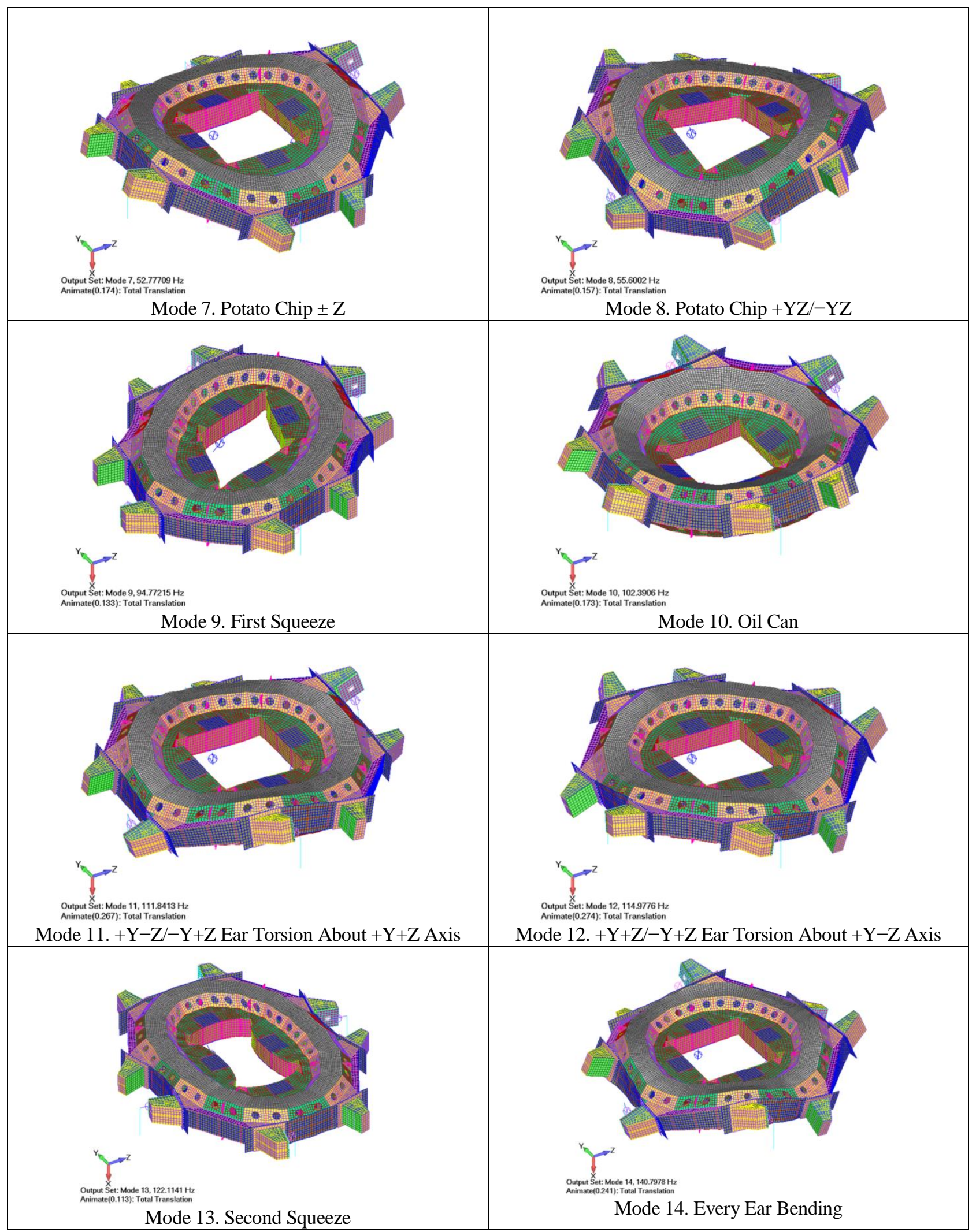

Fig 11 MVF Free-Free Mode Shapes 


\section{DATA ANALYSIS OF BARE MVF TABLE ON ACTUATORS}

To assess the feasibility of using the MVF table for fixed base modal testing, sine-sweep and random data from bare table testing were analyzed. A total of four tests were analyzed: X (vertical) sine sweep, Y (lateral) sine sweep, Z (lateral) sine sweep, and multi-DOF random with all actuators activated (X vertical configuration). A list of test runs is presented in Table 6. Over forty accelerometer channels were mounted on the MVF table, and forces were measured at a total of eleven out of a possible twenty actuators. Actuator forces were not measured directly. Instead, oil pressure in the double spherical couplings was used to estimate force in the vertical actuators, and actuator pressure differential was used to estimate force for the in-plane actuators. Pressure readings in nine of the sixteen vertical actuators were not measured, but at least one pressure in each four-actuator quadrant was measured. Future testing will record all pressures, but measurement of a reduced number of forces was sufficient for this preliminary test because at least one force associated with each of the eight individual sources was measured.

Table 6 Test Runs Analyzed

\begin{tabular}{|l|l|l|}
\hline Run Title & Configuration & Excitation \\
\hline SV0063_UFF.ATI & X (Vertical) & $5-150 \mathrm{~Hz}$ Sine Sweep \\
SV0098_UFF.ATI & Z (Lateral) & $5-150 \mathrm{~Hz}$ Sine Sweep \\
SV0110_UFF.ATI & Y (Lateral) & $5-150 \mathrm{~Hz}$ Sine Sweep \\
SV0115_UFF.ATI & X (Vertical) & $10 \mathrm{~min}$ Random \\
\hline
\end{tabular}

A test display model identifying the accelerometer locations and the actuator attachment point locations is presented in Fig 12 . Accelerometers were selected to be able to observe and differentiate the first six rigid body modes and several flexible body modes of the bare MVF table.

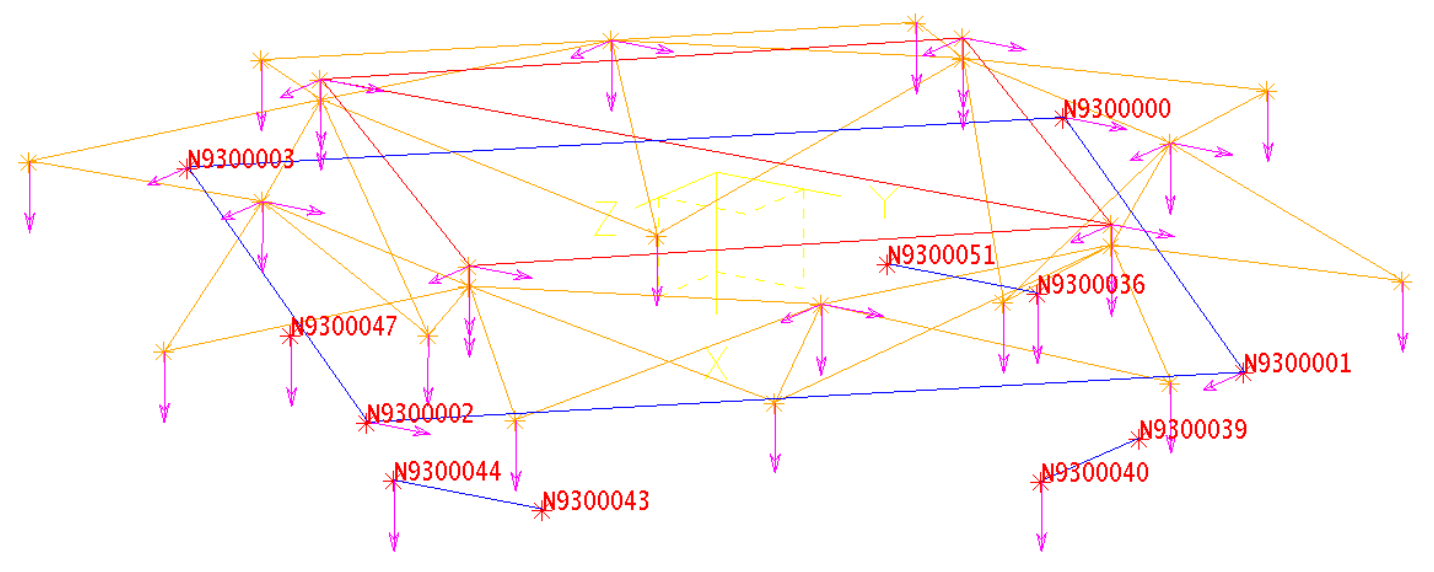

Fig 12 Test Display Model Showing Accelerometer and Load Cell Locations; Each Arrow Corresponds to an Accelerometer or Load Produced by the Actuators and Load Application Locations are Identified with Node Labels

\section{MVF Bare Table Sine-Sweep Test Data}

Acceleration and force time histories were collected with the MVF performing 5-150 Hz sine-sweep tests in the X-axis (vertical), Y-axis (lateral), and Z-axis (lateral) with a bare MVF Table. These tests were performed prior to installing the verification test article (VTA) in order to ring out basic system performance characteristics. For the X-axis shakes, all twenty actuators are active and driven by eight source signals, with the vertical actuators providing $\mathrm{X}$-axis translation and minimizing pitching about the lateral $\mathrm{Y}$ and $\mathrm{Z}$ axes and the horizontal actuators minimizing the lateral $\mathrm{Y}$ and $\mathrm{Z}$ axes translations. For the Y- and Z-axis shakes, the MVF table is locked down so that the vertical actuators are not active and only the horizontal actuators are active, producing translation in the shake axis and minimizing translation in the off-axis and rotation about the $\mathrm{X}$-axis.

The number of independent references that can be used to calculate FRFs is equal to the lesser of the number of independent source signals and the number of actuators. Since all of the source signals for the sine-sweep tests are correlated, only single 
reference FRFs can be calculated. Note that this reference can be a single data channel or a linear combination of channels. The acceleration/acceleration (A/A) FRFs computed here use the average acceleration in the drive direction of the MVF table as the reference.

One can view the resulting FRFs to determine the frequency at which the table moves in a non-drive direction, such as the table rocking. The FRF will be constant as a function of frequency if there are no dynamics. A summary plot of the FRFs for each of the three sweeps using the power spectrum mode indicator function (PSMIF) is presented in Fig 13, which can be used to observe the significant behavior of the table and shows the response of the table in the drive direction. The vertical configuration response is amplified above $30 \mathrm{~Hz}$, while the lateral configuration accelerometers start their amplification above $60 \mathrm{~Hz}$. It is expected that the maximum frequency for the lateral configuration will decrease as the size of the structure mounted to the table increases.

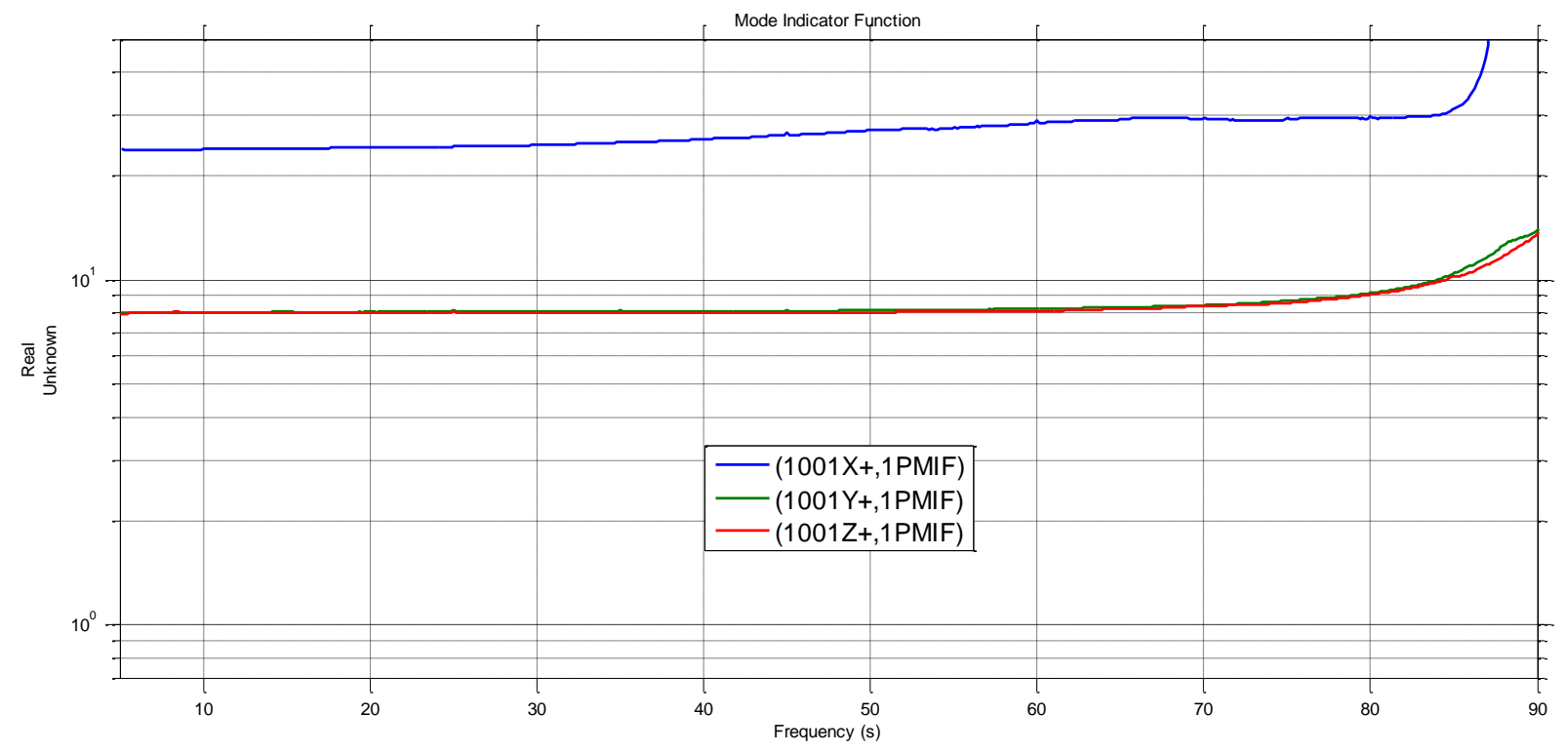

Fig 13 Sine-Sweep Test PSMIF Comparisons: 1001X+ X-Axis Shake Reference (Blue), 1001Y+ Y-Axis Shake Reference (Green), 1001Z+ Z-Axis Shake Reference (Red)

Lower-frequency dynamics are better viewed by observing accelerometer response in the off direction. The PSMIFs for each sine-sweep test, broken out by accelerometer direction, are presented in Fig 14. The X-direction response shows lowresponding, low-frequency modes below $20 \mathrm{~Hz}$, which are likely rigid body modes the controller is attempting to remove with the in-plane shakers. There is also a very highly damped dynamic amplification that peaks near $70 \mathrm{~Hz}$. There is very little dynamics associated with the $\mathrm{X}$-axis motion for the $\mathrm{Y}$ - and Z-direction sine sweeps below $80 \mathrm{~Hz}$. This is likely due to the fact that the vertical actuators are locked and not activated. The control system is doing a good job of minimizing the off-axis inplane motion in the Y- and Z-direction sine sweeps, but there is evidence of some dynamic amplification. 

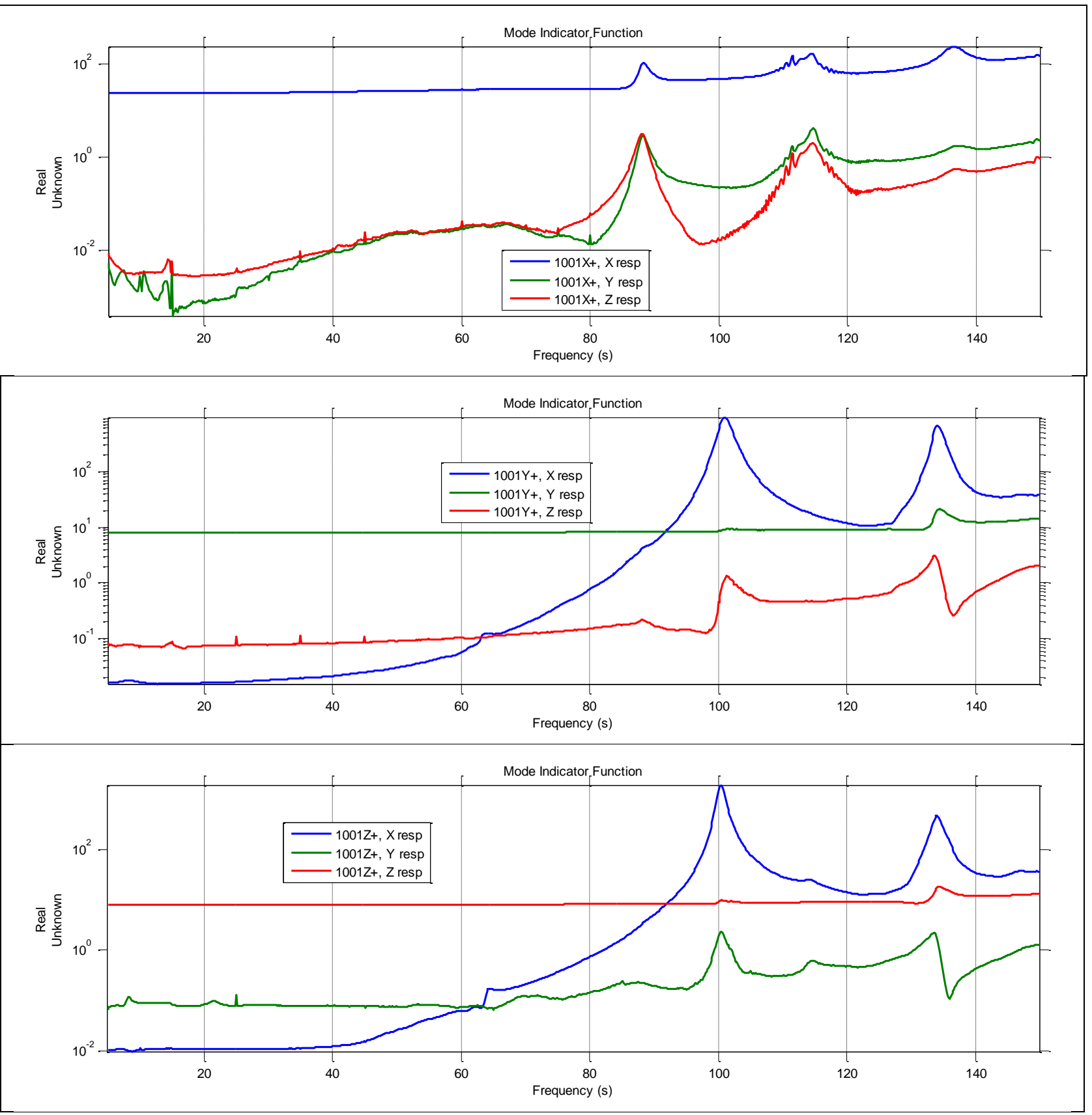

Fig 14 Power Spectrum Mode Indicator Functions for Sine-Sweep Tests by Accelerometer Group

\section{MVF Bare Table Random Data}

Ten minutes of low-level random base input using the eight independent actuator groups (four vertical, four lateral) from 5 to $150 \mathrm{~Hz}$ was collected when the MVF was configured for testing in the vertical direction. This random characterization run is necessary to provide the control system the transfer functions needed to provide a pure vertical $(\mathrm{X})$ direction sine-sweep excitation. A representative force measurement from each of the eight independent actuator groups was used to calculate acceleration/force (A/F) FRFs. Viewing the complex mode indicator function (CMIF) of the A/F FRF identifies the rigid body and flexible modes of the table (Fig 15). The reason the CMIF is used instead of the PSMIF is that the CMIF can identify closely spaced or lightly excited modes. Three rigid body modes are near $10 \mathrm{~Hz}$, and three more rigid body modes are below 5 $\mathrm{Hz}$. Flexible modes are observable beginning near $50 \mathrm{~Hz}$. 


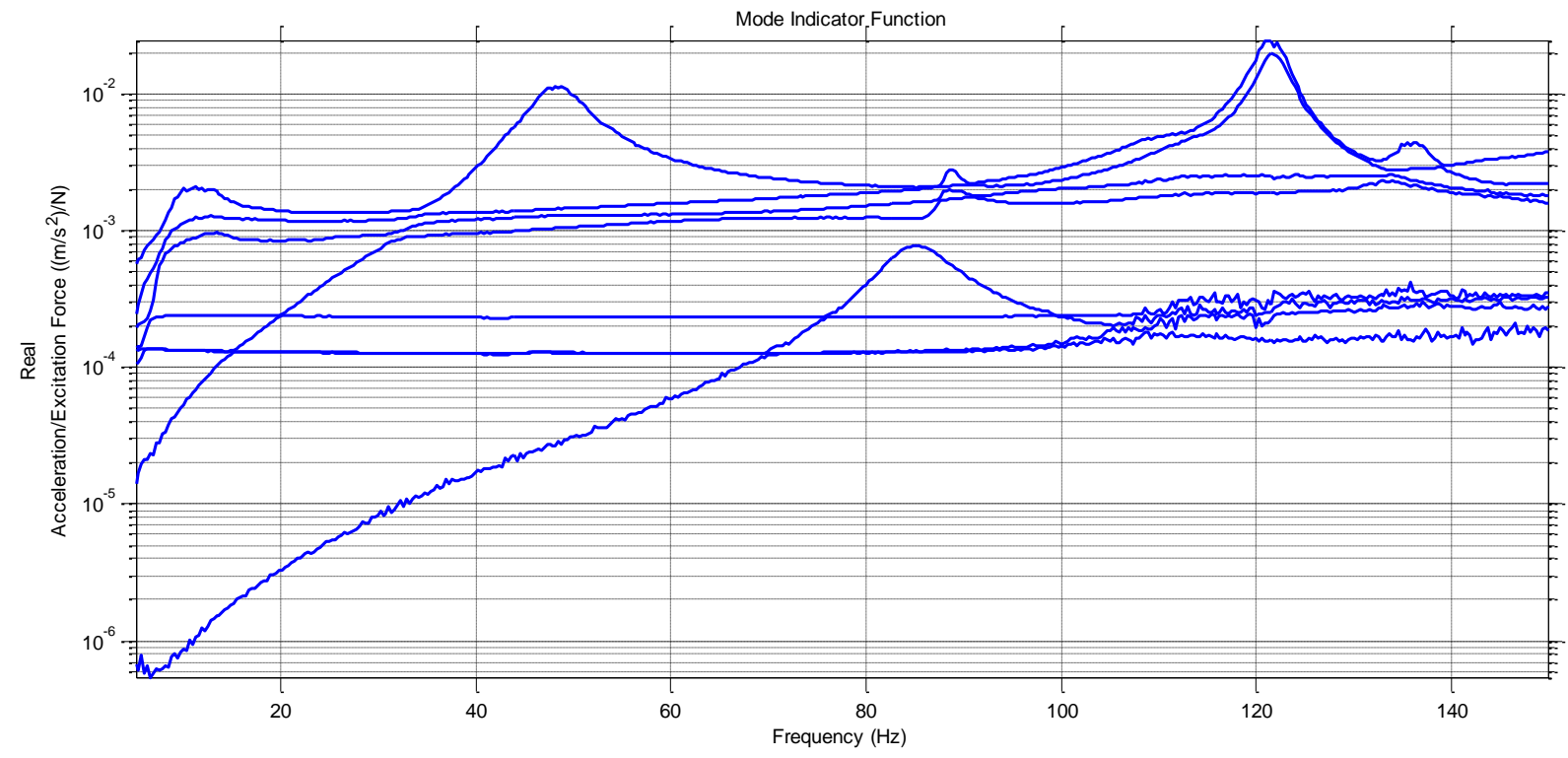

Fig 15 Complex Mode Indicator Function A/F FRF, with Six Flexible Table Modes Above $40 \mathrm{~Hz}$

While the complex mode indicator function clearly shows the resonant frequencies, there is a phase discrepancy for the primary mode at $48 \mathrm{~Hz}$. An example FRF plot is presented below. The phase should decrease through resonance, not increase; an increase in phase would correspond to negative damping. Increasing phase suggests that the indirect measure of force is not completely accurate. This is likely due to the fact that the vertical actuator oil column resonance is near $50 \mathrm{~Hz}$.

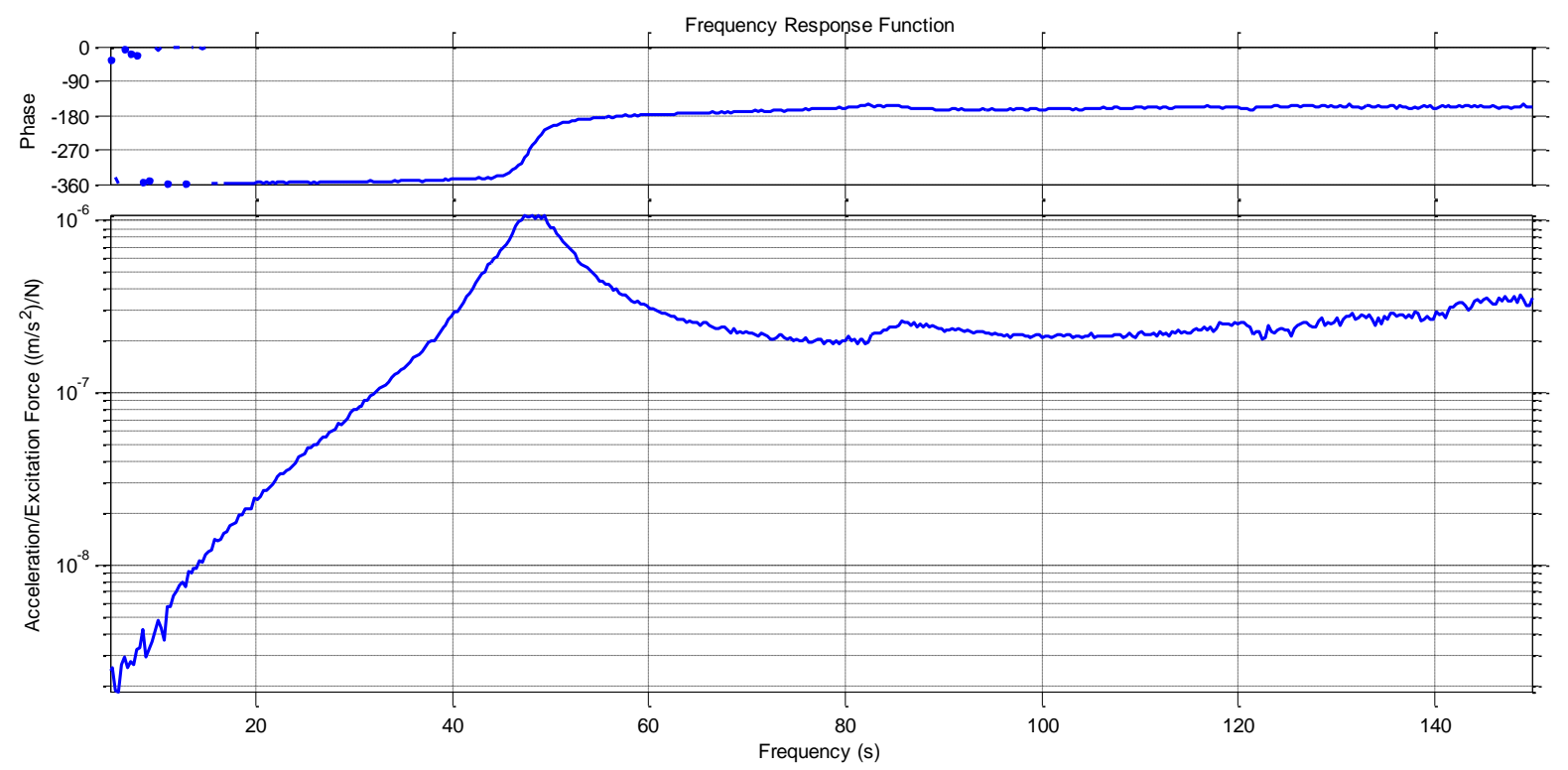

Fig 16 Representative A/F FRF: Increasing Phase at Resonance Indicates Negative Damping, Which Is Not Realizable in a Passive Structure 
The flexible body modes of the table are presented in Table 7. Plots of the modes are shown in Fig 17.

Table 7 Free-Free Table Modes

\begin{tabular}{|r|r|r|l|}
\hline $\begin{array}{c}\text { Mode } \\
\text { No. }\end{array}$ & $\begin{array}{c}\text { Freq } \\
\text { Hz }\end{array}$ & $\begin{array}{c}\text { Damp } \\
\text { \% crit }\end{array}$ & Description \\
\hline 1 & 47.9 & -3.3 & Potato-Chip \\
2 & 86.4 & 4.6 & Oil Can \\
3 & 87.9 & 2.3 & Squeeze \\
4 & 122.0 & 0.9 & 2nd Bending (1) \\
5 & 122.0 & 0.9 & 2nd Bending (2) \\
6 & 136.6 & 1.7 & Ear Twist \\
\hline
\end{tabular}

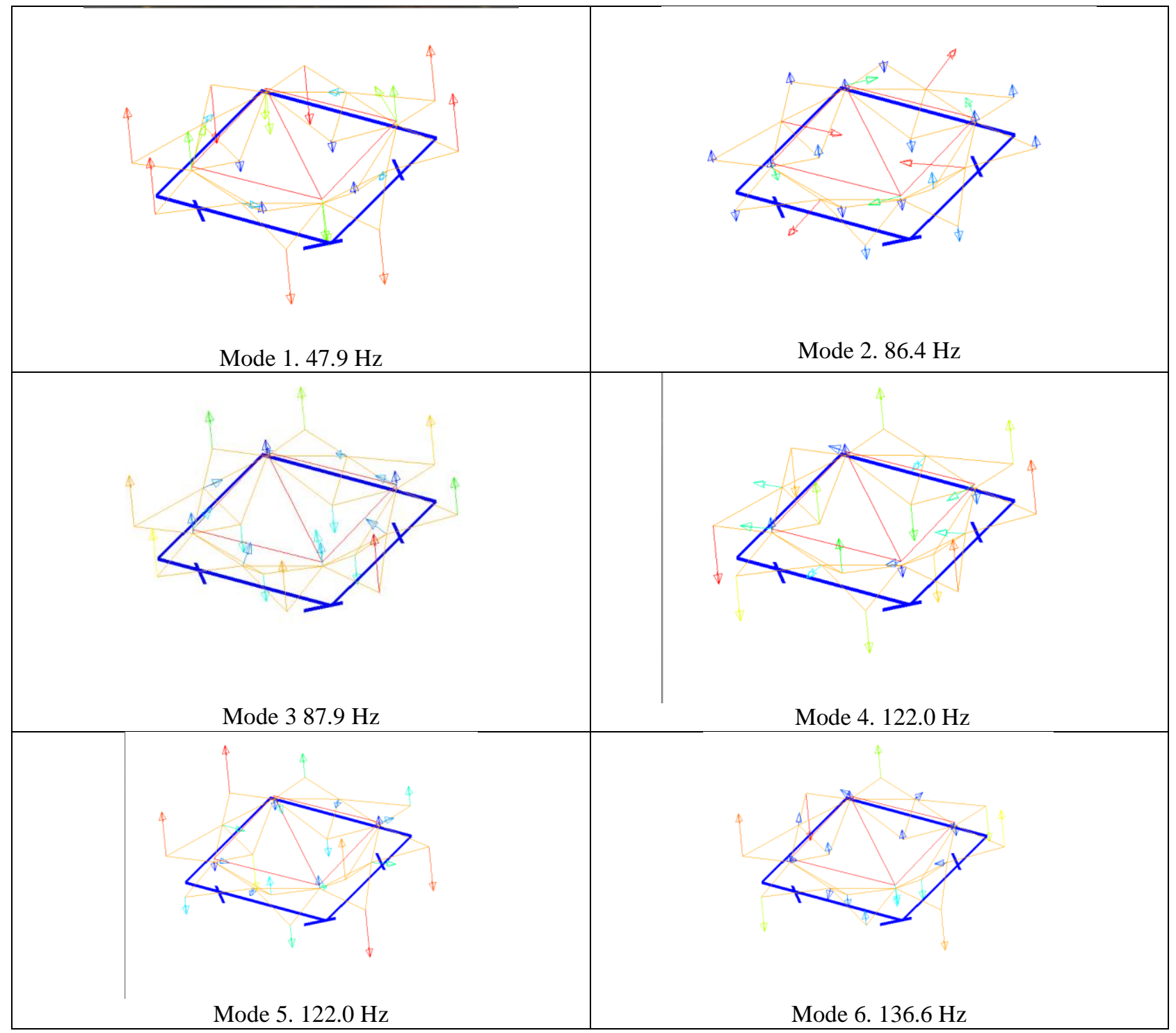

Fig 17 Bare Table Mode Shapes Using Actuator Forces as References

A comparison between extracted mode shapes with the MVF table in the test stand and the results from the MVF modal test is presented in Table 8. One "potato chip" mode and the second squeeze modes were not extracted from this data due to the actuator configuration not being able to excite them; the vertical actuators were installed in groups of four, and a node line for the second potato chip mode was between the second and third actuator. To excite this mode, the first two actuators in each set 
would need to apply a positive force while the second two actuators were applying a negative force. However, each set was linked so that all four actuators in each set input forces that all had the same sign; therefore, the mode was not excited. The second squeeze mode would likely require significant effort to extract since it is a low-responding in-plane mode that is excited by only two of the four in-plane actuators. The two highest-frequency modes appear to have moved outside the frequency range of the test. Modes 5 and 6 are highlighted since the shapes from the base shake test are a linear combination of the shapes extracted from the free-free modal survey; essentially these shapes are repeated roots, and having rotated modes is not unexpected.

Another item to note is that the frequencies are different between the two tests, and with the exception of the first mode, the damping from the base shake test is higher. The difference in frequencies is due to the difference in mass of the MVF table between the two configurations.

Table 8 Comparison Between Modal Tests

\begin{tabular}{|c|c|c|c|c|c|}
\hline & \multicolumn{2}{|c|}{ Base Shake } & \multicolumn{2}{|c|}{ Modal Test } & \\
\hline $\begin{array}{c}\text { Mode } \\
\text { No. }\end{array}$ & $\begin{array}{c}\text { Freq } \\
\mathrm{Hz}\end{array}$ & $\begin{array}{l}\text { Damp } \\
\% \text { crit }\end{array}$ & \begin{tabular}{|c} 
Freq \\
$\mathrm{Hz}$
\end{tabular} & $\begin{array}{l}\text { Damp } \\
\text { \% crit }\end{array}$ & Description \\
\hline 1 & 47.9 & -3.30 & 52.7 & 0.05 & Potato Chip +/-Z \\
\hline 2 & & & 55.0 & 0.11 & Potato Chip $+Y-Z /-Y+Z$ \\
\hline 3 & 87.9 & 2.34 & 96.2 & 0.03 & 1st Squeeze \\
\hline 4 & 86.4 & 4.59 & 102.8 & 0.07 & Oil Can \\
\hline 5 & 122.0 & 0.87 & 111.0 & 0.31 & $+Y-Z /-Y+Z$ Ear Torsion about $+Y+Z$ axis \\
\hline 6 & 122.0 & 0.87 & 114.8 & 0.06 & $+\mathrm{Y}+\mathrm{Z} /-\mathrm{Y}+\mathrm{Z}$ Ear Torsion about $+\mathrm{Y}-\mathrm{Z}$ axis \\
\hline 7 & & & 123.8 & 0.31 & 2nd Squeeze \\
\hline 8 & 136.6 & 1.69 & 140.7 & 0.05 & Ear Bending o-o-p with adjacent ear \\
\hline
\end{tabular}

The potential capability and limitation of using the FRF correction method to extract fixed base modes from MVF X-axis shake random tests can be assessed by using the FRF correction method on the MVF bare table X-axis shake random test data. Since there are currently eight independent references available, eight shapes can be removed from the table response. For this study, we chose the six rigid body modes based on the FEM geometry and the first two flexible body mode shapes, the $47.9 \mathrm{~Hz}$ potatochip mode and the $86.4 \mathrm{~Hz}$ oil can mode, which are shown in Fig 17. The four independent vertical actuator sets should be able to control rigid body vertical, tip, and tilt modes as well as the first out-of-plane flexible mode. The four independent in-plane actuator sets should be able to control rigid body lateral Y, lateral Z, and yaw, and the first in-plane flexible body mode.

PSMIFs using the six rigid body modes (1001X+through 1001RZ+), the first bending mode (1007X+), and the first in-plane mode $(1008 \mathrm{X}+)$ are presented in Fig 18 and Fig 19. The PSMIF was used here to visualize the dynamics of the system associated with each reference. There are no peaks in the FRFs until the frequency of the plunge mode near $88 \mathrm{~Hz}$. The FRF correction method was able to remove all six rigid body modes and the first two flexible body modes that are excited during $\mathrm{X}$-axis random shaking.

The PSMIF associated with the eighth mode shape that was removed, the first in-plane flexible body mode of the MVF bare table, has a much lower overall response than the other reference shapes. This is most likely because that excitation does not excite the vertical response of the MVF table. The PSMIF associated with the first out-of-plane mode has no dynamics below $150 \mathrm{~Hz}$, but the PSMIF begins to increase near $150 \mathrm{~Hz}$. Otherwise, the only rigid body shape that excites the oil can mode is the vertical rigid body shape $(1001 \mathrm{X}+)$, while the rigid body yaw shape $(1001 \mathrm{RX}+)$ excites the ear-twist mode. The other rigid body shapes excite the two second bending modes. 


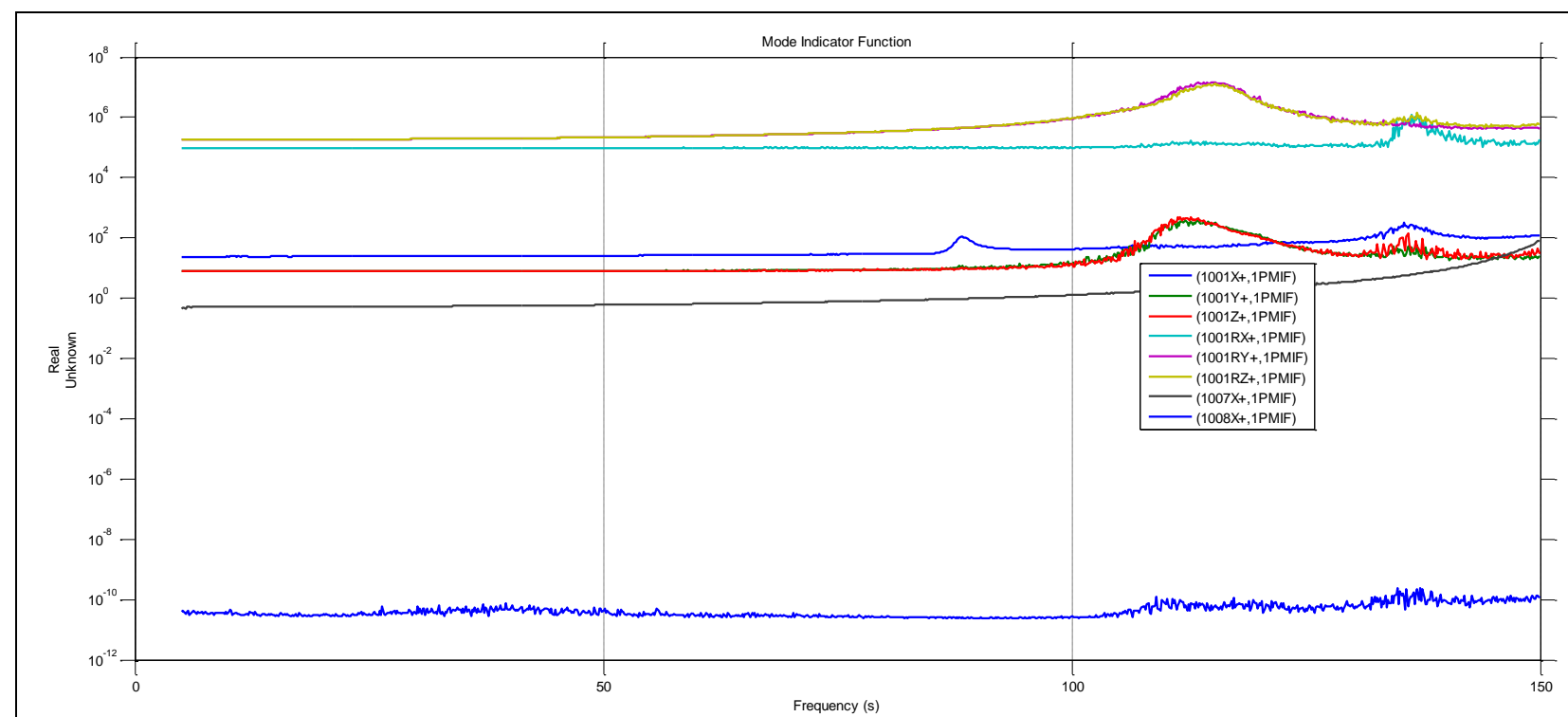

Fig 18 PSMIF for A/A FRFs of MVF Table

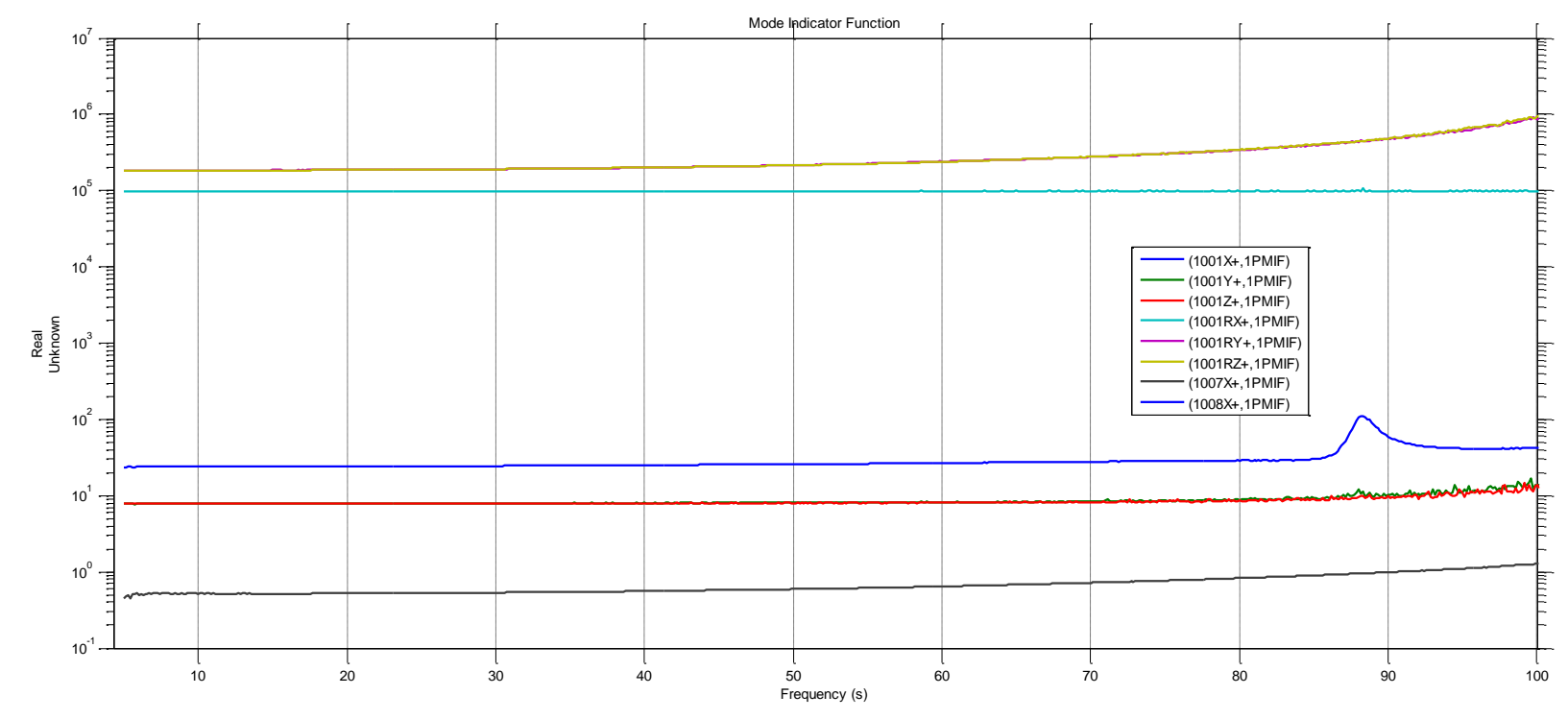

Fig 19 PSMIF for A/A FRFs of MVF Table - Close Up

There is a possibility that the other flexible modes could be controlled if the number of independent references were increased. An example would be to add four references to the control system and then group the vertical actuators into sets of two instead of four. However, the current system is not configured for twelve references. Even so, there are questions as to whether one could control the plunge mode since the vertical actuators are aligned such that they would use the same force pattern as the vertical rigid body mode. In other words, the mode shapes measured only from drive point accelerometers at each of the actuators would be the same for the vertical rigid body mode and the plunge mode. This suggests that one would need to add vertical actuators near the edges of the MVF table to be able to control the plunge mode.

Another potential way to remove more than two flexible body modes is to use the mode shape correction method. The mode shape correction method is not limited by the number of actuators and offers a possible method for preventing the higherfrequency modes from influencing the test results. However, it has a limitation that the mode shapes used in the method must be mass-normalized. Therefore it was not studied in this effort for two reasons:

1. Test-measured mass-normalized mode shapes could not be calculated because the shakers did not all have drive point accelerometers.

2. Negative damping in the primary flexible mode indicated that there was a test setup issue with the method for measuring actuator force. 
While drive-point accelerometers can be installed for future tests, there may not be a feasible method of accurately measuring vertical actuator force above $50 \mathrm{~Hz}$.

\section{SUMMARY}

This paper discussed preliminary analysis indicating the viability and frequency limitations of using the FRF correction method on MVF to be able to extract fixed base modal parameters from MVF X-axis vertical random shake tests. Being able to extract fixed base modal parameters using MVF would result in a significant reduction in testing schedule and risk to the test articles due to reduced handling.

The current MVF X-axis vertical random shake configuration uses eight independent references, which have been shown to be able to remove the effect of the six rigid body modes and two flexible modes. Additionally, the effect of higher frequency MVF table modes could potentially be removed if the vertical actuators were reconfigured into eight groups of two actuators each or the mode shape correction method was able to be implemented. Due to the current vertical actuator configuration and independent references, it may not be possible to remove the oil can mode without adding supplemental vertical actuators.

The next step in this effort is to perform two modal surveys on a representative test article called the verification test article (VTA). The first modal survey will be a traditional fixed base modal survey having the VTA mounted to the MVF modal floor. The second modal survey will be performed with the VTA mounted on the MVF table, MVF performing an X-axis vertical random shake test, and using the FRF correction method to extract fixed base modal parameters. The validity of the implementation of the FRF correction method on MVF will be accomplished by comparing the fixed base modal parameters extracted from these two modal surveys.

\section{REFERENCES}

[1] Carne, Thomas G., Martinez, David R., and Nord, Arlo R. "A Comparison of Fixed-Base and Driven Base Modal Testing of an Electronics Package." Proceedings of the Seventh International Modal Analysis Conference, Las Vegas, NV. 6729. February 1989.

[2] Beliveau, J.G., Vigneron, F.R., Soucy, Y., and Draisey, S. "Modal Parameter Estimation from Base Excitation.” Journal of Sound and Vibration 107, 435-49. 1986.

[3] Fullekrug, U. "Determination of Effective Masses and Modal Masses from Base-Driven Tests." Proceedings of the 14th International Modal Analysis Conference, Dearborn, MI. 671-81. 1996.

[4] Sinapius, J.M. "Identification of Fixed and Free Interface Normal Modes by Base Excitation." Proceedings of the 14th International Modal Analysis Conference, Dearborn, MI. 23-31. February 1996.

[5] Mayes, Randy L., and Bridgers, L. Daniel. "Extracting Fixed Base Modal Models from Vibration Tests on Flexible Tables." Proceedings of the $27^{\text {th }}$ International Modal Analysis Conference, Orlando, FL. February 2009.

[6] Napolitano, K., and Yoder, N. "Fixed Base FRF Using Boundary Measurements as References - Analytical Derivation." Proceedings of the 30 International Modal Analysis Conference, Jacksonville, FL. February 2012.

[7] Napolitano, K., and Yoder, N. "Fixed Base FRF Using Boundary Measurements as References - Analytical Derivation." Proceedings of the $30^{\text {th }}$ International Modal Analysis Conference, Jacksonville, FL. February 2012.

[8] Mayes, R., Rohe, D., and Blecke, J. "Extending the Frequency Band for Fixed Base Modal Analysis on a Vibration Slip Table." Proceedings of the $31^{\text {th }}$ International Modal Analysis Conference, Jacksonville, FL. February 2013.

[9] Napolitano, K., and Yoder, N. "Extraction of Fixed-Base Modes of a Structure Mounted on a Shake Table," Proceedings of the $31^{\text {th }}$ International Modal Analysis Conference, Jacksonville, FL. February 2013. 